\title{
Questions on Percutaneous Patent Foramen Ovale Closure for Secondary Stroke Prevention: The Heads of the Lernaean Hydra
}

\author{
Leonidas Palaiodimos ${ }^{\mathrm{a}}$ Damianos G. Kokkinidis ${ }^{\mathrm{b}}$ \\ a Division of Hospital Medicine, Department of Medicine, Montefiore Medical Center, Albert Einstein College of \\ Medicine, Bronx, NY, USA; ${ }^{b}$ Department of Medicine, Jacobi Medical Center, Albert Einstein College of Medicine, \\ Bronx, NY, USA
}

Foramen ovale is one of the essential shunts of the fetal blood flow allowing oxygenated blood to enter the systemic circulation. At birth, as the lungs expand, and oxygen fills the alveoli, the variety of subsequent hemodynamic changes that occur make this shunt unnecessary and gradually lead to its physiologic closure [1]. However, foramen ovale remains open in about $25 \%$ of the adults [2]. This condition is called patent foramen ovale (PFO). Although most individuals with a PFO remain asymptomatic throughout their lives, PFO has been associated with several disease entities, such as cerebral and systemic embolism, migraine with aura, hypoxemia-related conditions, and decompression sickness [3-6]. Ischemic stroke secondary to paradoxical embolism is the most thoroughly studied among the PFO-mediated conditions. It was in 1877, when Cohnheim [7] first reported the case of a young woman who was diagnosed with an occluded cerebral artery, PFO, and deep vein thrombosis. Since then and mainly in the last 20 years, manifold realword studies offered unequivocal evidence that $\mathrm{PFO}$ is a risk factor for ischemic cerebral vascular accidents. The question for years was whether we should close the PFOs in patients who had a prior stroke. Until 2017, randomized clinical trials (RCTs) had ambiguous results. How-

\section{KARGER}

(c) 2019 S. Karger AG, Basel

E-Mail karger@karger.com

www.karger.com/crd ever, three new RCTs and the long-term results of a fourth one, all of them published in the last 2 years, changed our perspective on PFO closure [8-12].

In this issue of Cardiology, Garg et al. [13] reported the results of a meta-analysis of all six randomized trials. In total, 3,747 patients, all of them younger than 65 , were included (closure arm: 1,889; medical therapy arm: 1,858). A random effects model was used to obtain pooled effect estimates. The meta-analysis revealed a significant reduction in the primary endpoint (risk of recurrent stroke) for the closure group compared to medical therapy (RR 0.41; 95\% CI 0.20-0.83). However, the subgroup analysis for the shunt size revealed that the benefit was mainly driven by patients with moderate or large shunts (RR 0.35; 95\% CI 0.18-0.68), while there was no difference between patients with small shunts (RR 0.98 ; $95 \%$ CI $0.56-1.73$ ). The closure arm was found to have a higher risk for atrial fibrillation (AF) (RR 5.29, 95\% CI 2.18-43.63).

The authors should be congratulated for their well-designed and conducted analysis, which comes to be added in a number of already published meta-analyses on this topic [14-17]. The main message of the meta-analysis is that PFO closure is beneficial for the prevention of recurrent stroke in non-elderly patients with moderate or large shunts. At 
this point, it should be noted that atrial septal aneurysm, eustachian valve, and the Chiari network are also considered high-risk features and enhanced reasons for PFO closure [18]. Another major finding of this analysis is that PFO closure was associated with a five-fold increase in the risk for AF. However, it is important to mention that the majority of the new-onset AF events happened for a brief period, early after the procedure, and for the most part neither led to an ischemic stroke nor required long-term anticoagulation. This has also been shown by real-world data, where $<4 \%$ of the new-onset AF cases related to PFO closure did actually progress to permanent AF [19].

Despite the progress in our understanding of PFO closure indications, benefits and risks, there are still questions to be answered. First, while high-risk PFOs seem to clearly benefit from closure, PFOs that do not share highrisk features are still a matter of debate. No difference was found in this meta-analysis, but the REDUCE trial showed that closure can be effective regardless of the shunt size [9]. Second, elderly subjects ( $>65$ years old) were excluded from all six RCTs, and thus current knowledge is limited regarding PFO closure benefits for the elderly. How should primary care physicians and cardiologists manage elderly patients with embolic strokes of undetermined source where the only workup finding is a PFO? Takafuji et al. [20] have recently published a small cohort of 14 elderly patients $(75.2 \pm 6.5$ years old $)$ with a history of ischemic stroke and a high-risk PFO, who underwent PFO closure. No recurrent stroke events were noted after $2.6 \pm 1.8$ years of follow-up. Unless industry is willing to sponsor a new large RCT including the aforementioned groups of patients (low-risk PFOs and the elderly), the answer can be potentially provided from large, well-conducted, prospective registries. Third, the duration and the exact type of an antithrombotic regimen after PFO closure is still uncertain, and weighing the risks of bleeding and the benefits of protection from device-related thrombotic events is really difficult. All trials used antiplatelet therapy to lower the risk of device-related thrombotic events, but the duration varied. A recently published prospective study showed that early (within 1 year) discontinuation of the antithrombotic regimen is not associated with a higher risk of ischemic cerebrovascular events, but the small sample in this subgroup was a major limitation [21]. PFO closure is not the only percutaneous intervention where the duration of antithrombotic treatment is still under question; similar debates exist for the postprocedural management of transcatheter aortic valve replacement or percutaneous coronary interventions with drug-eluting stents.

In summary, we now have undisputable evidence that PFO closure decreases the risk of a recurrent stroke in well-selected patients; yet the more answers we get, the more questions arise as the heads of the Lernaean Hydra.

\section{Disclosure Statement}

The authors declare that they have no conflicts of interest to disclose.

\section{Funding Sources}

No funding was available for this study.

\section{References}

1 Kiserud T. Physiology of the fetal circulation. Semin Fetal Neonatal Med. 2005 Dec;10(6): 493-503.

2 Hagen PT, Scholz DG, Edwards WD. Incidence and size of patent foramen ovale during the first 10 decades of life: an autopsy study of 965 normal hearts. Mayo Clin Proc. 1984 Jan; 59(1):17-20.

3 Johnson BI. Paradoxical embolism. J Clin Pathol. 1951 Aug;4(3):316-32.

4 Moon RE, Camporesi EM, Kisslo JA. Patent foramen ovale and decompression sickness in divers. Lancet. 1989 Mar;1(8637):513-4.

5 Tobis JM, Charles A, Silberstein SD, Sorensen S, Maini B, Horwitz PA, et al. Percutaneous closure of patent foramen ovale in patients with migraine: the PREMIUM trial. J Am Coll Cardiol. 2017 Dec;70(22):2766-74.
6 Mojadidi MK, Ruiz JC, Chertoff J, Zaman MO, Elgendy IY, Mahmoud AN, et al. Patent foramen ovale and hypoxemia. Cardiol Rev. $2019 \mathrm{Jan} / \mathrm{Feb} ; 27(1): 34-40$.

7 Cohnheim J. Vorlesungen Uber Allgemenie Pathologie. 1877;1:1.

8 Meier B, Kalesan B, Mattle HP, Khattab AA, Hildick-Smith D, Dudek D, et al.; PC Trial Investigators. Percutaneous closure of patent foramen ovale in cryptogenic embolism. N Engl J Med. 2013 Mar;368(12):1083-91.

9 Søndergaard L, Kasner SE, Rhodes JF, Andersen G, Iversen HK, Nielsen-Kudsk JE, et al.; Gore REDUCE Clinical Study Investigators. Patent foramen ovale closure or antiplatelet therapy for cryptogenic stroke. N Engl J Med. 2017 Sep;377(11):1033-42.
10 Lee PH, Song JK, Kim JS, Heo R, Lee S, Kim $\mathrm{DH}$, et al. Cryptogenic stroke and high-risk patent foramen ovale: the DEFENSE-PFO trial. J Am Coll Cardiol. 2018 May;71(20):233542.

11 Mas JL, Derumeaux G, Guillon B, Massardier E, Hosseini $\mathrm{H}$, Mechtouff $\mathrm{L}$, et al.; CLOSE Investigators. Patent foramen ovale closure or anticoagulation vs. antiplatelets after stroke. N Engl J Med. 2017 Sep;377(11): 1011-21.

12 Saver JL, Carroll JD, Thaler DE, Smalling RW, MacDonald LA, Marks DS, et al.; RESPECT Investigators. Long-term outcomes of patent foramen ovale closure or medical therapy after stroke. N Engl J Med. 2017 Sep;377(11): 1022-32. 
13 Garg A, Thawabi M, Rout A, Sossou C, Cohen M, Kostis JB. Recurrent Stroke Reduction with Patent Foramen Ovale Closure versus Medical Therapy Based on PFO Characteristics: A Meta-Analysis of Randomized Controlled Trials. Cardiology. DOI: 10.1159/ 000500501.

14 Kokkinidis DG, Palaiodimos L, Mastoris I, Karamanis D, Faillace RT. The best DEFENSE for high-risk patent foramen ovale: an updated meta-analysis of six randomized trials. Arch Cardiovasc Dis. 2019 Mar;112(3): 150-152.

15 Mojadidi MK, Elgendy AY, Elgendy IY, Mahmoud AN, Elbadawi A, Eshtehardi P, et al. Transcatheter patent foramen ovale closure after cryptogenic stroke: an updated metaanalysis of randomized trials. JACC Cardiovasc Interv. 2017 Nov;10(21):2228-30.
16 Ntaios G, Papavasileiou V, Sagris D, Makaritsis $\mathrm{K}$, Vemmos K, Steiner T, et al. Closure of patent foramen ovale versus medical therapy in patients with cryptogenic stroke or transient ischemic attack: updated systematic review and meta-analysis. Stroke. 2018 Feb;49(2):412-8.

17 Ando T, Holmes AA, Pahuja M, Javed A, Briasoulis A, Telila T, et al. Meta-analysis comparing patent foramen ovale closure versus medical therapy to prevent recurrent cryptogenic stroke. Am J Cardiol. 2018 Mar;121(5): 649-55.

18 Mojadidi MK, Zaman MO, Elgendy IY, Mahmoud AN, Patel NK, Agarwal N, et al. Cryptogenic stroke and patent foramen ovale. J Am Coll Cardiol. 2018 Mar;71(9):1035-43.
19 Staubach S, Steinberg DH, Zimmermann W, Wawra $\mathrm{N}$, Wilson $\mathrm{N}$, Wunderlich $\mathrm{N}$, et al. New onset atrial fibrillation after patent foramen ovale closure. Catheter Cardiovasc Interv. 2009 Nov;74(6):889-95.

20 Takafuji H, Hosokawa S, Ogura R, Hiasa Y. Percutaneous transcatheter closure of highrisk patent foramen ovale in the elderly. Heart Vessels. 2019. Epub ahead of print.

21 Wintzer-Wehekind J, Alperi A, Houde C, Côté JM, Guimaraes LF, Côté M, et al. Impact of Discontinuation of Antithrombotic Therapy Following Closure of Patent Foramen Ovale in Patients With Cryptogenic Embolism. Am J Cardiol. 2019 May;123(9):153845. 